\title{
Face the food: Food plating with facial patterns influences appetite and event-related brain potentials
}

\author{
Daniela Schwab ${ }^{1} \cdot$ Sasa Zorjan $^{1,2} \cdot$ Anne Schienle ${ }^{1}{ }^{10}$ \\ Accepted: 1 December 2020 / Published online: 17 December 2020 \\ (c) The Author(s) 2020
}

\begin{abstract}
The presentation of visual food cues (e.g., food plating) can affect our appetite and leads to characteristic changes of early as well as late positivity in the electroencephalogram. The present event-related potential (ERP) study attempted to change ERPs and affective ratings for food pictures by rearranging the components of a depicted meal (conventional presentation) as a smiley or frowny. The images were presented to 68 women (mean age $=24$ years), who rated the wanting and liking of the meals. Compared to conventional food plating, smiley and frowny meals elicited enhanced amplitudes of the P200, P300, and late positive potential (LPP) in a large occipito-parietal cluster. Frowny meals were rated as less appetizing than conventional food presentations. The mentioned ERP components are concomitants of face configuration processing (P200), automatic attention/novelty detection (P300), and voluntary attention/assignment of emotional meaning (LPP). Thus, the combination of two affective cues (food, face) in one stimulus changed the activation in motivational circuits of the brain. Also, serving a meal as a frowny could help to regulate appetite.
\end{abstract}

Keywords Food plating $\cdot$ ERPs $\cdot$ Frowny $\cdot$ Smiley $\cdot$ Appetite

\section{Introduction}

Cues in our environment that signal reward or punishment reflexively activate fundamental motivational circuits in the brain prompting heightened attention and selection of appropriate action (Bradley et al. 2012). Food cues, such as images of food, are types of reward stimuli that are associated with 'motivated attention' and characteristic changes in the electroencephalogram (EEG). Images of food elicit elevated amplitudes of the P300 and late positive potential (LPP) compared to non-food (examples of studies with healthy individuals Blechert et al. 2014a; Nijs et al. 2010; Sarlo et al. 2013; Stockburger et al. 2008, 2009). The enhancement of late positivity (P300, LPP) is more pronounced for cues of high-calorie vs. low-calorie food (Asmaro and Liotti 2014; Schwab et al. 2017; Toepel et al. 2009).

Anne Schienle

anne.schienle@uni-graz.at

1 Institute of Psychology, University of Graz, BioTechmed Graz, Universitätsplatz 2/III, 8010 Graz, Austria

2 Department of Psychology, Faculty of Arts, University of Maribor, Maribor, Slovenia
EEG research on affective picture processing has identified modulations of P300/LPP amplitudes very consistently (for a review see Olofsson et al. 2008). The P300 (a positive deflection in the EEG starting approximately $300 \mathrm{~ms}$ after stimulus onset) and the LPP (a positive deflection in the EEG that follows the P300 and can last up to $6000 \mathrm{~ms}$; Cuthbert et al. 2000) are most enhanced for pictures rated highest in emotional arousal, regardless of whether they depict appetitive (e.g., food) or aversive (e.g., violence) contents (Schupp et al. 2004). It has been suggested that both ERP components reflect the amount of visual attention devoted to a stimulus (Schupp et al. 2004). The P300 has been associated with automatic attention (initial attention capture), whereas LPP modulations are dominant during controlled (voluntary) and sustained attention allocation (e.g., (Hajcak et al. 2010); for a factor-analytic component selection approach see Foti et al. 2009). The LPP is sensitive to (re) appraisal manipulations which alter the meaning attributed to an emotional stimulus (e.g., Moser et al. 2006), while the P300 can be changed through manipulations of directed attention (through instructions or task requirements; Ferrari et al. 2008; Thiruchselvam et al. 2011).

Affective facial expressions are another class of cues that elicit 'motivated attention' (Bradley et al. 2012). EEG 
research has demonstrated that images depicting emotional faces (e.g., happy or sad faces) prompt increased late positivity (P300, LPP) compared to neutral faces (for a review see Eimer and Holmes 2007). Also, earlier components, such as the N170 and the P200 have been associated with face processing. The amplitude of the N170 is higher for faces compared to non-facial stimuli (Yovel 2016). The P200 is related to the analysis of the visual characteristics of the face. Some researchers have suggested that the P200 reflects a perceptual matching process, which compares the incoming sensory information with an internal representation or expectation (e.g., Freunberger et al. 2007; Itier and Taylor 2002; Luck and Hillyard 1994). Differences in P200 amplitudes have been observed when comparing responses to pictures of real faces with faces of cartoon figures, and faces from different ethnic backgrounds (e.g., He et al. 2019; Stahl et al. 2010). Thus, the P200 is a concomitant of face configuration processing.

In the present ERP study, the participants were presented with visual food cues in the form of facial expressions. We administered images depicting three presentation types of different sweet and salty dishes (e.g., burgers, sweet snacks). The elements of a dish were either arranged like a smiley, a frowny, or in a conventional manner. For example, a meal consisting of a burger with French fries as a side dish was rearranged. The tomato slices in the burger were used as eyes, the French fries as hair, and parts of the bun formed the mouth. The corners of the mouth pointed up or down to create a happy or sad expression on the 'burger face'. Thus, we combined two types of motivational cues in one stimulus (food and face). The processing of these concurrent cues should influence each other, and influence the mentioned ERP components.

Additionally, the presentation of food as faces might influence emotional responses to these stimuli. Previous research has shown that meal arrangements have a great influence on appetite, food liking, and eating behavior (for reviews of findings from normal-weight individuals see Piqueras-Fiszman and Spence 2015; Sørensen et al. 2003; Spence et al. 2016). For example, Zellner et al. (2010) showed that both the complexity and balance of the elements in a dish exerted a significant effect on the perceived attractiveness of a meal and the willingness to eat it. Michel et al. (2014) demonstrated that the placing of the elements of a salad in an art-inspired manner (similar to a Kandinsky painting) compared to a conventional presentation (with all of the elements of the salad tossed together) increased ratings of liking and tastiness for the salad.

The exposure to a visual food cue can be a starting signal for eating. In environments with a high density of foodrelated cues in combination with easy food access, overeating is easily provoked (see meta-analysis by Boswell and Kober 2016). A study by Calitri et al. (2010) found that heightened attention to food cues predicted weight gain over 1 year in a student population. Given the current obesity crisis, it would seem advisable to develop easy-touse strategies that can reduce food cue reactivity.

As to the best of our knowledge, electrocortical and emotional responses to food plating in the form of facial expressions have not been investigated so far. It was investigated if meal presentations (smiley, frowny, conventional) can influence the amplitudes of those ERPs (P200, P300, LPP) that are associated with the integrated processing of facial features (P200), automatic attention (P300), and controlled attention and meaning attribution (LPP). Additionally, we analyzed whether the mentioned types of meal presentations can influence affective ratings (e.g., reduced wanting and liking of frowny meals compared to conventional meal arrangements), and computed correlations between electrocortical and self-report measures.

\section{Methods}

\section{Participants}

A total of 68 women were recruited through local advertisements at the university campus, and in social media. The sample was restricted to women because of gender differences regarding food preferences and craving (for reviews see Hallam et al. 2016; Herman and Polivy 2010). Participants' age ranged between 18 and 37 years $(\mathrm{M}=24.31, \mathrm{SD}=3.99)$. The women had a high school diploma $(51.5 \%)$ or a university diploma $(48.5 \%)$.

The participants completed the eating disorder examination questionnaire (EDE-Q; Hilbert et al. 2007) which measures the presence of eating disorder symptoms (e.g., eating concerns, weight concerns) on 7-point Likert scales $(0=$ not at all, $6=$ markedly $)$. Cronbach's alpha of the total scale was .93. Compared to the questionnaire norms, the present sample had a reduced total EDE-Q score $(\mathrm{p}=.005)$. Thus, the reported eating/weight concerns were below average. The self-reported body mass index (BMI) ranged from 16.85 to $32.11 \mathrm{~kg} / \mathrm{m}^{2}(M=22.41, S D=3.25)$. Exclusion criteria for the study were past and current reported neurological diseases and mental disorders.

All participants gave written informed consent prior to study participation. The study was approved by the ethics committee of the university and was conducted in accordance with the Declaration of Helsinki. We conducted a power analysis in G*Power (Faul et al. 2007) for withinsubject designs. In order to detect small to medium effect sizes (due to possible small differences between different affective presentations; partial $\eta^{2}=.02$ ) and achieve a 
power at or above .95 at the alpha level of .05 , we would need a sample of 64 participants.

\section{Stimuli}

\section{Development and evaluation of visual stimuli}

A set of 66 pictures of different sweet and salty meals was created. Each meal was presented on a white dinner plate on a black background. Food components were arranged in the form of a smiley, a frowny and without a facial pattern (i.e., conventional food presentation; see Fig. 1). Twenty-two pictures per category were presented.

The picture set was piloted on a group of 41 students (63.4\% female) with a mean age of 22.73 years $(S D=2.11)$. The participants rated the meals according to liking ("how much do you like the presented meal?") and wanting ("how much do you want to eat the presented meal at the moment?") on 9-point Likert scales ( $1=$ not at all; $9=$ very much). The reported average hunger level of the participants at the time of testing was $\mathrm{M}=4.51(\mathrm{SD}=2.34$; possible range $1-9 ; 9=$ very hungry).

A repeated measures analysis of variance (ANOVA) was conducted to test the effects of food PRESENTATION (smiley, frowny, conventional) on liking and wanting of the meal. For both ratings, a significant main effect of PRESENTATION emerged (liking: $F(1.57,62.73)=8.85$, $p<.001, \eta_{p}{ }^{2}=.18$; wanting: $F(1.59,63.52)=13.86, p<.001$, $\left.\eta_{p}{ }^{2}=.26\right)$. For liking, frowny meals $(M=4.64, S D=1.42)$ received lower ratings compared to conventional presentation $(M=5.01, S D=1.33, p<.001)$, and smiley meals $(M=5.03, S D=1.51 p=.01)$. There was no difference in liking between smileys and conventional presentations $(\mathrm{p}=.40)$.

Wanting ratings were lower for frownies $(M=3.39$, $S D=1.41)$ compared to conventional meal presentations
$(M=3.88, S D=1.57, p<.001)$, and smileys $(M=4.10$, $S D=1.73, p<.001)$. Wanting ratings for smileys and conventional presentations did not differ from each other $(p=.23)$.

\section{Visual stimuli for the present study}

We selected a subset of 48 pictures from the pilot study (balanced ratio of salty and sweet meals). Each picture category (smiley, frowny, conventional) consisted of 16 pictures. The three picture categories did not differ in physical image properties that influence visual attention: color, object size, complexity (proportion of outlinerelated pixels within the picture), and brightness (mean difference between each non-white pixel and the white background; all $\mathrm{p}>.60$ ). The image properties were compared using customized scripts written in Matlab (Blechert et al. 2014b). Each image of a meal was presented twice. The participants, therefore, viewed a total of 96 pictures. The pictures were shown in randomized order for $1500 \mathrm{~ms}$ each and were preceded by a fixation cross (500-1000 ms). Twelve pictures (four pictures per category randomly selected before the experiment) were rated by the participants according to liking and wanting on 9-point Likert scales $(1=$ not at all; $9=$ very much $)$. Each participant rated the same pictures.

\section{Procedure}

The participants were instructed to fast for at least $3 \mathrm{~h}$ before attending the laboratory session. At the beginning of the experiment, the participants were asked to rate their current hunger level on a 9-point Likert scale $(9=$ very

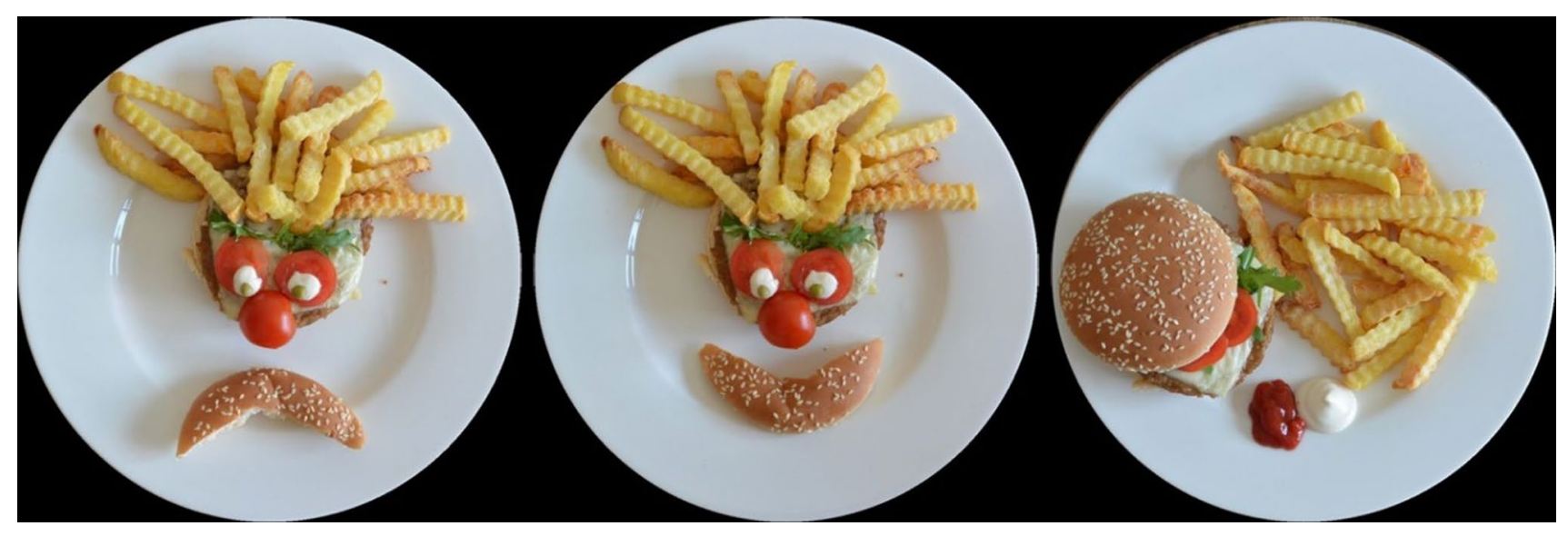

Fig. 1 Example of the three types of meal presentations 
high) $(M=4.60, S D=2.35)$. Then, the $E E G$ electrodes were attached and the picture presentation started.

\section{Electrophysiological recordings and data analyses}

Data were recorded via an actiCHamp system (actiCHamp, Brain Products GmbH, Gilching, Germany) with 63 active actiCAP snap electrodes (according to the 10-10 system at Fp1, Fz, F3, F7, FT9, FC5, FC1, C3, T7, TP9, CP5, CP1, $\mathrm{Pz}, \mathrm{P} 3, \mathrm{P} 7, \mathrm{O} 1, \mathrm{Oz}, \mathrm{O} 2, \mathrm{P} 4, \mathrm{P} 8, \mathrm{TP} 10, \mathrm{CP} 6, \mathrm{CP} 2, \mathrm{Cz}, \mathrm{C} 4$, T8, FT10, FC6, FC2, F4, F8, Fp2, AF7, AF3, AFz, F1, F5, FT7, FC3, C1, C5, TP7, CP3, P1, P5, PO7, PO3, POz, PO4, PO8, P6, P2, CPz, CP4,TP8,C6, C2, FC4, FT8, F6, AF8, $\mathrm{AF} 4, \mathrm{~F} 2)$. The reference electrode was placed on position $\mathrm{FCz}$, the ground electrode on position FPz. An electrolyte gel was applied to each electrode to keep electrode impedances below $20 \mathrm{k} \Omega$.

The BrainVision recorder (version 1.21) was used for data recording (sampling rate $=2500 \mathrm{~Hz}$; passband: 0.016-1000 Hz) and the BrainVision Analyzer (version 2.0.4) for data analysis. The sampling rate was set to $250 \mathrm{~Hz}$. The data were re-referenced to averaged mastoid electrodes (i.e., TP9 and TP10). Artifacts due to eye movements were corrected via the implemented ICA ocular correction software. Other artifact episodes (e.g., facial muscle activation) were excluded after visual inspection (percentage of artifactfree trials: $\mathrm{M}=91 \%$; $\mathrm{SD}=5.9 \%$ ).

The data were segmented into $1700 \mathrm{~ms}$ intervals $(200 \mathrm{~ms}$ pre-stimulus, $1500 \mathrm{~ms}$ post-stimulus) and corrected to the $200 \mathrm{~ms}$ pre-stimulus baseline (i.e. subtraction of the averaged baseline from all points in the post-stimulus segment). A $30 \mathrm{~Hz}$ low-pass filter was applied. The data were averaged separately for each condition. Based on previous research (e.g., Sarlo et al. 2013; Svaldi et al. 2010; Zorjan et al. 2020), and cortical maps depicting the local distribution of ERPs, we extracted ERPs for the time windows 180-230 ms (P200), 300-400 ms (P300), 400-1500 ms (LPP) at a parieto-occipital cluster (CP5, CP3, CP1, CPz, CP2, CP4, CP6, P7, P5, P3, P1, Pz, P2, P4, P6, P8, PO7, $\mathrm{PO} 3, \mathrm{POz}, \mathrm{PO} 4, \mathrm{PO} 8)$. Exploratory analyses for earlier ERP components (P100, N170) revealed no effects and are therefore not reported.

\section{Statistical analyses}

We performed repeated measures ANOVA to test the effects of food PRESENTATION (smiley, frowny, conventional) on food wanting/liking (the average rating across the pictures of a category) and amplitudes of the P200/P300/LPP. If assumptions of sphericity were violated, we report Greenhouse-Geisser corrected degrees of freedom. We report $\eta 2 p$ $\left(\right.$ partial eta $\left.{ }^{2}\right)$ as effect size measure. Significant effects were followed up with post-hoc comparisons (corrected for multiple testing). All analyses were conducted with SPSS (version 25).

\section{Results}

\section{Picture ratings}

\section{Liking}

The main effect of PRESENTATION was significant $\left(\mathrm{F}(1.63,109.31)=9.55, \mathrm{p}<.001, \eta_{\mathrm{p}}{ }^{2}=.13\right)$. Frowny meals $(\mathrm{M}=5.91, \mathrm{SD}=1.31)$ received lower ratings than conventional presentations $(\mathrm{M}=6.33, \mathrm{SD}=1.04)$ and smileys $(\mathrm{M}=6.19, \mathrm{SD}=1.23$; both $\mathrm{p}=.002)$. Conventional meal presentations and smileys did not differ from each $(\mathrm{p}=.41)$.

\section{Wanting}

The main effect of PRESENTATION was significant $\left(\mathrm{F}(1.71,114.22)=5.42, \mathrm{p}=.008, \eta_{\mathrm{p}}{ }^{2}=.08\right)$. Meals presented as frowny $(\mathrm{M}=4.84, \mathrm{SD}=1.59)$ received lower ratings than conventional plating $(\mathrm{M}=5.13, \mathrm{SD}=1.63, \mathrm{p}=.01)$. Smileys $(\mathrm{M}=4.99, \mathrm{SD}=1.67)$ and conventional meal presentations did not differ from each other $(\mathrm{p}=.38)$.

\section{ERP analyses}

Grand averages for the three types of meal presentations are displayed in Fig. 2.

\section{P200}

The main effect of PRESENTATION was significant $\left(\mathrm{F}(1.83,122.91)=31.15, \mathrm{p}<.001, \eta_{\mathrm{p}}{ }^{2}=.32\right)$. Post-hoc comparisons indicated that $\mathrm{P} 200$ amplitudes for meals arranged as smiley $(\mathrm{M}=5.30, \mathrm{SD}=2.90)$ and frowny $(\mathrm{M}=5.53$, $\mathrm{SD}=3.36$ ) were higher compared to conventionally arranged meals $(\mathrm{M}=3.67, \mathrm{SD}=3.13$; all $\mathrm{p}<.001)$.

\section{P300}

The main effect of PRESENTATION was significant $\left(\mathrm{F}(2,134)=15.41, \mathrm{p}<.001, \eta_{\mathrm{p}}{ }^{2}=.19\right)$. P300 amplitudes for meals arranged as smiley $(\mathrm{M}=5.74, \mathrm{SD}=2.70)$ and frowny $(\mathrm{M}=5.64, \mathrm{SD}=3.03)$ were higher compared to conventionally arranged meals $(\mathrm{M}=4.49, \mathrm{SD}=2.75$; all $\mathrm{p}<.001)$. 

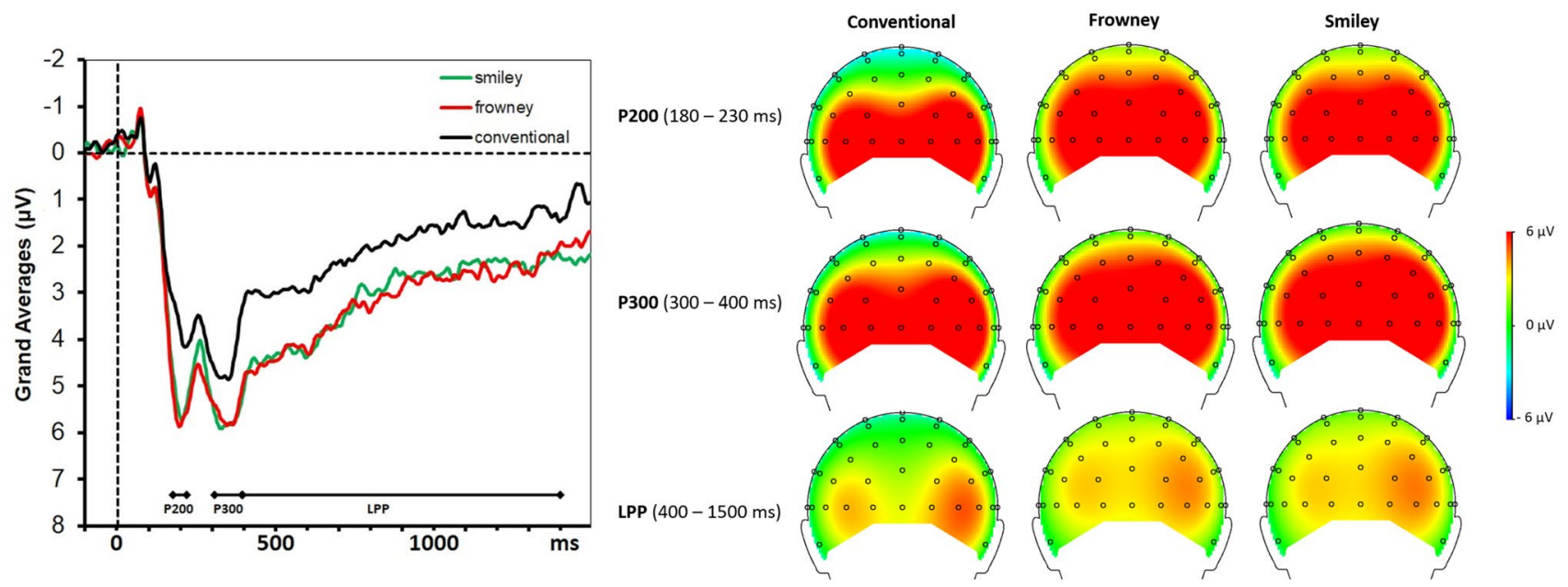

Fig. 2 Grand averages and headmaps for the three types of meal presentations for the parieto-occipital cluster

Table 1 Pearson correlations (and $\mathrm{p}$ values in brackets) between changes in wanting and liking of frowny meals and ERP components

\begin{tabular}{llll}
\hline & P200 & P300 & \multicolumn{1}{c}{ LPP } \\
\hline $\begin{array}{l}\text { Liking } \\
\text { (frowny-con- }\end{array}$ & $-.236(.050)$ & $-.187(.128)$ & $.011(.928)$ \\
$\begin{array}{l}\text { ventional) } \\
\text { Wanting } \\
\text { (frowny-con- } \\
\text { ventional) }\end{array}$ & $-.271(.025)$ & $-.197(.107)$ & $-.040(.745)$ \\
\hline
\end{tabular}

\section{LPP}

The effect PRESENTATION of was significant $\left(\mathrm{F}(1.66,111.08)=13.88, \mathrm{p}<.001, \eta_{\mathrm{p}}{ }^{2}=.17\right)$. LPP amplitudes for meals arranged as a smiley $(\mathrm{M}=3.12, \mathrm{SD}=2.41)$ and frowny $(\mathrm{M}=3.23, \mathrm{SD}=2.93)$ were higher compared to conventionally arranged meals $(\mathrm{M}=2.07, \mathrm{SD}=2.08$; all $\mathrm{p}<.001)$.

\section{Correlation analyses}

In order to follow up on the effect of food plating on affective ratings for the meal and event-related positivity, we performed correlational analyses. We first computed difference scores for the ERP measures (e.g. P200_frowny minus P200_conventional) and the ratings (e.g., wanting_frowney minus wanting_conventional). These difference scores were correlated with each other.

The difference scores for the wanting/liking of frowny meals were negatively correlated with the P200 amplitude. A reduction in reported appetite for frownies was associated with a higher P200 amplitude (Table 1). The difference scores for the wanting/liking of smiley meals were not significantly correlated with the ERP amplitudes (all p > .17). Additionally, the EDE_Q score and the BMI were not associated with the computed difference scores (ERPs; wanting/liking; all p > .31).

\section{Discussion}

In the present study, we demonstrated that food plating with facial patterns can influence event-related brain potentials and the liking/wanting of a meal presentation. Food components arranged like a smiley or frowny elicited greater amplitudes of the P200, the P300, and the LPP than conventional meals. This increased early and late positivity was present in a large cluster across parietal and occipital electrode sites.

Elevated amplitudes of the P200 have been repeatedly identified in studies on visual food cue processing (e.g., Hume et al. 2015) and affective face processing (e.g., Eimer and Holmes 2007). This early positivity is associated with the identification and discrimination of stimulus features and the processing of stimulus configurations. For example, Portella et al. (2014) showed that the amplitude of the P200 component was significantly correlated with the reaction time in a visual discrimination task. He et al. (2019) administered images depicting real faces and faces of cartoon figures. Participants who excessively played internet games showed an elevated P200 amplitude to cartoon faces (compared to real faces). Thus, the P200 is a concomitant of higher-order perceptual processing and comparisons of sensory inputs with stored memories (e.g., Freunberger et al. 2007).

Smiley and frowny meals not only elicited enhanced early positivity but also late positivity (P300, LPP). The P300 is sensitive to interventions that change automatic attention (Hajcak et al. 2010). It has been shown that infrequently occurring events, deviant and novel events are 
associated with increased P300 amplitudes (for a review see Friedman et al. 2002). The frontal 'P3a' component is thought to reflect the activation of an attentional switching mechanism, while the parietal 'P3b' component is a concomitant of task-relevant novelty detection that involves a decision (Friedman et al. 2002). It is possible that the 'food faces' (smiley/frowny) which had to be evaluated according to food wanting were perceived as deviations from the expected conventional food plating and were therefore accompanied by the 'novelty P300'.

The observed LPP modulations typically accompany more ongoing, elaborative processing of motivationally relevant stimuli (e.g., Hajcak et al. 2010; Olofsson et al. 2008). Moreover, the LPP amplitude can be altered by changing the emotional meaning of stimuli (e.g., Moser et al. 2006). In the present investigation, increases in late positivity did not differ between the two emotionally-valenced configurations (i.e., smiley and frowny meals). This is in line with previous studies of affective picture processing, which show that P300/LPP amplitudes are enhanced for emotionally arousing pictures, regardless of valence (Schupp et al. 2004).

The rating data indicated that a change in emotional meaning was restricted to the frowny meals, which reduced the wanting and liking of the depicted food. Meals arranged as a frowny were rated as less pleasant and appetizing than conventional presentations. The ratings for smiley meals did not differ from conventional plating. This finding differs from the results of the pilot study. Here, the appetite ratings had been higher for smiley meals compared to the other two picture categories. The sample-specific findings may point to different attitudes toward the chosen style of food plating. Some participants indicated that the smiley meals reminded them of their childhood when their mothers had attempted to influence their eating behavior with a similar strategy.

The correlation analysis for the present data showed that the reduction of the reported wanting (and liking) of a frowny meal (compared to conventional plating) correlated with the average P200 amplitude. Greater appetite reductions were associated with higher amplitudes. Because the P200 is a concomitant of comparison processes (sensory inputs vs. expectations), higher amplitudes might reflect a greater perceived deviation (and aberration) from an expected meal presentation, which in turn is associated with the reduced motivational value of the meal. However, changes in motivational value should also have been correlated with changes in LPP amplitudes (e.g., Moser et al. 2006). Several factors might have reduced the 'frowny/smiley effect' and the associated correlations in the present study.

First, the ratings for the liking and wanting of conventionally arranged food were not very high on average. The selection of meals that are perceived as very appetizing (e.g. favorite meals of participants) could provoke greater emotional differentiation effects between frownys and conventional meal presentations. Second, individual characteristics of the participants, such as mood or liking of cartoon faces (frowny/smiley) possibly influence the responses to the stimuli (e.g., see $\mathrm{He}$ et al. 2019). Greater differentiation effects may also occur in individuals with increased food cue reactivity (e.g., participants with overweight/obesity/eating disorders). Such variables need to be assessed in future studies. Third, we did not measure food intake (e.g., the amount eaten in a frowny meal compared to a conventional meal) to study the impact of our experimental manipulation on food approach/avoidance. Furthermore, future studies could also include a neutral face food plating condition, which would enable us to disentangle the studied effects in more detail.

In conclusion, the present study demonstrated that food plating with facial patterns can change specific ERP components that are associated with the processing of facial features (P200), automatic attention capture/novelty detection (P300), and controlled attention/meaning attribution (LPP). Additionally, frowny arrangements changed self-reports regarding the wanting and liking of the meal. Serving a meal as a frowny could, therefore, help to regulate appetite.

Funding Open Access funding provided by University of Graz. This research received no funding.

\section{Compliance with ethical standards}

Conflict of interest The authors declare no conflict of interest.

Open Access This article is licensed under a Creative Commons Attribution 4.0 International License, which permits use, sharing, adaptation, distribution and reproduction in any medium or format, as long as you give appropriate credit to the original author(s) and the source, provide a link to the Creative Commons licence, and indicate if changes were made. The images or other third party material in this article are included in the article's Creative Commons licence, unless indicated otherwise in a credit line to the material. If material is not included in the article's Creative Commons licence and your intended use is not permitted by statutory regulation or exceeds the permitted use, you will need to obtain permission directly from the copyright holder. To view a copy of this licence, visit http://creativecommons.org/licenses/by/4.0/.

\section{References}

Asmaro, D., \& Liotti, M. (2014). High-caloric and chocolate stimuli processing in healthy humans: An integration of functional imaging and electrophysiological findings. Nutrients, 6(1), 319-341. https://doi.org/10.3390/nu6010319.

Blechert, J., Goltsche, J. E., Herbert, B. M., \& Wilhelm, F. H. (2014a). Eat your troubles away: Electrocortical and experiential correlates of food image processing are related to emotional eating style and emotional state. Biological Psychology, 96, 94-101. https://doi. org/10.1016/j.biopsycho.2013.12.007. 
Blechert, J., Meule, A., Busch, N. A., \& Ohla, K. (2014b). Food-pics: An image database for experimental research on eating and appetite. Frontiers in Psychology, 5, 617. https://doi.org/10.3389/fpsyg .2014.00617.

Boswell, R. G., \& Kober, H. (2016). Food cue reactivity and craving predict eating and weight gain: A meta-analytic review. Obesity Reviews, 17(2), 159-177. https://doi.org/10.1111/obr.12354.

Bradley, M. M., Keil, A., \& Lang, P. J. (2012). Orienting and emotional perception: Facilitation, attenuation, and interference. Frontiers in Psychology, 3, 493. https://doi.org/10.3389/fpsyg.2012.00493.

Calitri, R., Pothos, E. M., Tapper, K., Brunstrom, J. M., \& Rogers, P. J. (2010). Cognitive biases to healthy and unhealthy food words predict change in BMI. Obesity, 18(12), 2282-2287. https://doi. org/10.1038/oby.2010.78.

Cuthbert, B. N., Schupp, H. T., Bradley, M. M., Birbaumer, N., \& Lang, P. J. (2000). Brain potentials in affective picture processing: Covariation with autonomic arousal and affective report. Biological Psychology, 52(2), 95-111. https://doi.org/10.1016/ S0301-0511(99)00044-7.

Eimer, M., \& Holmes, A. (2007). Event-related brain potential correlates of emotional face processing. Neuropsychologia, 45(1), 15-31. https://doi.org/10.1016/j.neuropsychologia.2006.04.022.

Faul, F., Erdfelder, E., Lang, A.-G., \& Buchner, A. (2007). G*power 3: A flexible statistical power analysis program for the social, behavioral, and biomedical sciences. Behavior Research Methods, 39(2), 175-191. https://doi.org/10.3758/BF03193146.

Ferrari, V., Codispoti, M., Cardinale, R., \& Bradley, M. M. (2008). Directed and motivated attention during processing of natural scenes. Journal of Cognitive Neuroscience, 20(10), 1753-1761. https://doi.org/10.1162/jocn.2008.20121.

Foti, D., Hajcak, G., \& Dien, J. (2009). Differentiating neural responses to emotional pictures: Evidence from temporal-spatial PCA. Psychophysiology, 46(3), 521-530. https://doi.org/10.111 1/j.1469-8986.2009.00796.x.

Freunberger, R., Klimesch, W., Doppelmayr, M., \& Höller, Y. (2007). Visual P2 component is related to theta phase-locking. Neuroscience Letters, 426(3), 181-186. https://doi.org/10.1016/j.neule t.2007.08.062.

Friedman, D., Cycowicz, Y. M., \& Gaeta, H. (2002). The novelty P3: An event-related brain potential (ERP) sign of the brain's evaluation of novelty. Neuroscience and Biobehavioral Reviews, 25, 355-373.

Hajcak, G., MacNamara, A., \& Olvet, D. M. (2010). Event-related potentials, emotion, and emotion regulation: An integrative review. Developmental Neuropsychology, 35(2), 129-155. https://doi. org/10.1080/87565640903526504.

Hallam, J., Boswell, R. G., DeVito, E. E., \& Kober, H. (2016). Genderrelated differences in food craving and obesity. The Yale Journal of Biology and Medicine, 89(2), 161-173.

He, J., Zheng, Y., Fan, L., Pan, T., \& Nie, Y. (2019). Automatic processing advantage of cartoon face in internet gaming disorder: Evidence from P100, N170, P200, and MMN. Frontiers in Psychiatry, 10, 824. https://doi.org/10.3389/fpsyt.2019.00824.

Herman, C. P., \& Polivy, J. (2010). Sex and gender differences in eating behavior. In J. C. Chrisler \& D. R. McCreary (Eds.), Handbook of gender research in psychology 10.1007/978-1-4419-14651_22 (pp. 455-469). New York: Springer New York. https://doi. org/10.1007/978-1-4419-1465-1_22.

Hilbert, A., Tuschen-Caffier, B., Karwautz, A., Niederhofer, H., \& Munsch, S. (2007). Eating Disorder ExaminationQuestionnaire. Diagnostica, 53(3), 144-154. https://doi. org/10.1026/0012-1924.53.3.144.

Hume, D. J., Howells, F. M., Rauch, H. L., Kroff, J., \& Lambert, E. V. (2015). Electrophysiological indices of visual food cue-reactivity. Differences in obese, overweight and normal weight women. Appetite, 85, 126-137. https://doi.org/10.1016/j.appet.2014.11.012.
Itier, R. J., \& Taylor, M. J. (2002). Inversion and contrast polarity reversal affect both encoding and recognition processes of unfamiliar faces: A repetition study using ERPs. NeuroImage, 15(2), 353-372. https ://doi.org/10.1006/nimg.2001.0982.

Luck, S. J., \& Hillyard, S. A. (1994). Electrophysiological correlates of feature analysis during visual search. Psychophysiology, 31(3), 291-308. https://doi.org/10.1111/j.1469-8986.1994.tb02218.x.

Michel, C., Velasco, C., Gatti, E., \& Spence, C. (2014). A taste of Kandinsky: Assessing the influence of the artistic visual presentation of food on the dining experience. Flavour, 3(1). https://doi. org/10.1186/2044-7248-3-7.

Moser, J. S., Hajcak, G., Bukay, E., \& Simons, R. F. (2006). Intentional modulation of emotional responding to unpleasant pictures: An ERP study. Psychophysiology, 43(3), 292-296. https://doi.org/10. 1111/j.1469-8986.2006.00402.x.

Nijs, I. M. T., Muris, P., Euser, A. S., \& Franken, I. H. A. (2010). Differences in attention to food and food intake between overweight/ obese and normal-weight females under conditions of hunger and satiety. Appetite, 54(2), 243-254. https://doi.org/10.1016/j.appet .2009.11.004.

Olofsson, J. K., Nordin, S., Sequeira, H., \& Polich, J. (2008). Affective picture processing: An integrative review of ERP findings. Biological Psychology, 77(3), 247-265. https://doi.org/10.1016/j.biops ycho.2007.11.006.

Piqueras-Fiszman, B., \& Spence, C. (2015). Sensory expectations based on product-extrinsic food cues: An interdisciplinary review of the empirical evidence and theoretical accounts. Food Quality and Preference, 40, 165-179. https://doi.org/10.1016/j.foodq ual.2014.09.013

Portella, C., Machado, S., Paes, F., Cagy, M., Sack, A. T., SandovalCarrillo, A., \& Arias-Carrión, O. (2014). Differences in early and late stages of information processing between slow versus fast participants. International Archives of Medicine, 7(1), 49. https://doi. org/10.1186/1755-7682-7-49.

Sarlo, M., Übel, S., Leutgeb, V., \& Schienle, A. (2013). Cognitive reappraisal fails when attempting to reduce the appetitive value of food: An ERP study. Biological Psychology, 94(3), 507-512. https://doi. org/10.1016/j.biopsycho.2013.09.006.

Schupp, H. T., Öhman, A., Junghöfer, M., Weike, A. I., Stockburger, J., \& Hamm, A. O. (2004). The facilitated processing of threatening faces: An ERP analysis. Emotion, 4(2), 189-200. https://doi. org/10.1037/1528-3542.4.2.189.

Schwab, D., Giraldo, M., Spiegl, B., \& Schienle, A. (2017). Disgust evoked by strong wormwood bitterness influences the processing of visual food cues in women: An ERP study. Appetite, 108, 51-56. https://doi.org/10.1016/j.appet.2016.09.023.

Sørensen, L. B., Møller, P., Flint, A., Martens, M., \& Raben, A. (2003). Effect of sensory perception of foods on appetite and food intake: A review of studies on humans. International Journal of Obesity, 27(10), 1152-1166. https://doi.org/10.1038/sj.ijo.0802391.

Spence, C., Okajima, K., Cheok, A. D., Petit, O., \& Michel, C. (2016). Eating with our eyes: From visual hunger to digital satiation. Brain and Cognition, 110, 53-63. https://doi.org/10.1016/j.bandc .2015.08.006.

Stahl, J., Wiese, H., \& Schweinberger, S. R. (2010). Learning task affects ERP-correlates of the own-race bias, but not recognition memory performance. Neuropsychologia, 48(7), 2027-2040. https://doi. org/10.1016/j.neuropsychologia.2010.03.024.

Stockburger, J., Weike, A. I., Hamm, A. O., \& Schupp, H. T. (2008). Deprivation selectively modulates brain potentials to food pictures. Behavioral Neuroscience, 122(4), 936-942. https://doi.org/10.1037/ a0012517.

Stockburger, J., Schmälzle, R., Flaisch, T., Bublatzky, F., \& Schupp, H. T. (2009). The impact of hunger on food cue processing: An eventrelated brain potential study. NeuroImage, 47(4), 1819-1829. https ://doi.org/10.1016/j.neuroimage.2009.04.071. 
Svaldi, J., Tuschen-Caffier, B., Peyk, P., \& Blechert, J. (2010). Information processing of food pictures in binge eating disorder. Appetite, 55(3), 685-694. https://doi.org/10.1016/j.appet.2010.10.002.

Thiruchselvam, R., Blechert, J., Sheppes, G., Rydstrom, A., \& Gross, J. J. (2011). The temporal dynamics of emotion regulation: An EEG study of distraction and reappraisal. Biological Psychology, 87(1), 84-92. https://doi.org/10.1016/j.biopsycho.2011.02.009.

Toepel, U., Knebel, J.-F., Hudry, J., Le Coutre, J., \& Murray, M. M. (2009). The brain tracks the energetic value in food images. NeuroImage, 44(3), 967-974. https://doi.org/10.1016/j.neuroimage .2008 .10 .005

Yovel, G. (2016). Neural and cognitive face-selective markers: An integrative review. Neuropsychologia, 83, 5-13. https://doi. org/10.1016/j.neuropsychologia.2015.09.026.
Zellner, D. A., Lankford, M., Ambrose, L., \& Locher, P. (2010). Art on the plate: Effect of balance and color on attractiveness of, willingness to try and liking for food. Food Quality and Preference, 21(5), 575-578. https://doi.org/10.1016/j.foodqual.2010.02.007.

Zorjan, S., Schwab, D., \& Schienle, A. (2020). The effects of imaginary eating on visual food cue reactivity: An event-related potential study. Appetite, 153, 104743. https://doi.org/10.1016/j.appet.2020.104743.

Publisher's Note Springer Nature remains neutral with regard to jurisdictional claims in published maps and institutional affiliations. 